\title{
Innovative co-evaluation and co-creation of an online learning programme with de Bono's 'Six Thinking Hats'
}

\author{
Kath MacDonald, Iddo Oberski, Amanda Stears, Kim Christie \\ Queen Margaret University
}

\section{Context and historical background}

Online learning is a growth industry and worldwide numbers are set to grow still further as institutions reach out to more diverse markets (Butcher and Rose-Adams 2015). However, there is a suggestion that Higher Education Institutions' (HEIs) processes, pedagogies and philosophies in relation to online learning are not always fit for purpose (O' Shea et al, 2015). Such an approach may have significant impact on attrition rates for postgraduate online learners, especially those studying part-time, with competing family and work responsibilities (Fragoso et al, 2013). A notable example is transition arrangements for online learners. Mechanisms appropriate for inducting students undertaking face-to-face programmes have been found wanting when deployed for online learners (Brown et al, 2015). Institutions using such traditional induction programmes demonstrate poor conception of what it is like to study online and, moreover, of what support mechanisms are required to assist those moving into this new mode of learning.

Queen Margaret University, Edinburgh, Scotland, is, within the landscape of HEls in Scotland and the UK, a relatively small university. It was founded in 1875 and has always focused on improvement of the quality of life. Courses are professionally and vocationally relevant and, through its international links, its approaches to learning and teaching are farreaching.

The PgCert in Professional and Higher Education has run since 2001 as a blended-learning programme, until its re-design as an online programme in 2015. The blended programme comprised three days' attendance with homework, online resources and discussion boards. The online programme has four core modules totalling sixty Level 11 credits (equivalent to approximately 600 hours of student effort) and is part-time, usually over two years. It is preceded by an optional online induction module. Students are generally mature, predominantly female and largely consist of new academics, working in HEls across a range of disciplines, and health professionals who have a teaching remit to their role. Many of these professionals have little experience of online learning and need support in developing their digital literacy (Jisc, 2014). The transition to the e-PgCert has presented opportunities and challenges for students and the programme team, some of whom are online novices themselves.

\section{Specifications of the project}

The aim of the project was to gain an in-depth knowledge of the student and staff experiences of transitioning to online learning, based upon our evaluation of the first year of the e-PgCert. We gathered feedback from both groups, with the intention of co-creating recommendations to enhance both the student and staff experience of the e-PgCert. Two students on the programme who were fulfilling roles as student representatives were invited to become co-researchers (Figure 1). In previous years, no student representatives had come forward, owing, probably, to the demographic of the cohort (professional, mature, part- 


\section{Case Studies}

time), with many fulfilling multiple roles besides that of being a student. However, in the first year of the e-PgCert, we managed successfully to have two student volunteers to act as representatives. We also gained funding that afforded an awayday for the research team. Both students were pleased to have the opportunity to engage in co-creation activities.

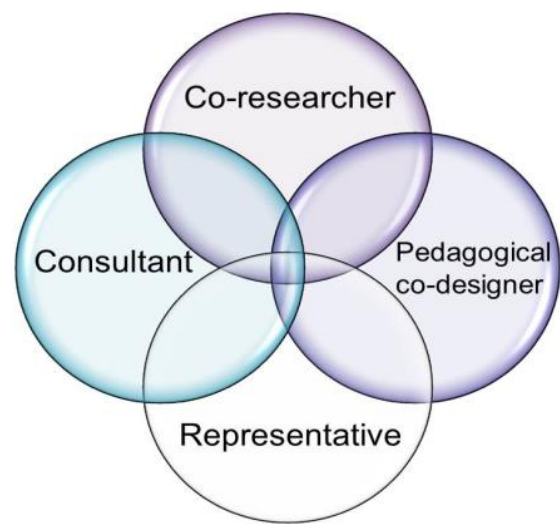

Figure 1. Student roles in co-creation of learning and teaching (from Bovill et al, 2016)

Research questions for this case study:

- What are staff expectations of supporting learners to transition to online learning?

- What are learner expectations, and experiences, of the support they receive in transitioning to online learning?

- What are the experiences of staff in the preparation, design and maintenance of supporting an online programme?

- How, and in what ways, can staff and learners work in partnership to enrich the support mechanisms provided for learners transitioning online?

- What lessons have been learned for future implementation of online learning at the institutional and postgraduate programme levels?

The aims and research questions align with the broader aims of the QAA Enhancement Theme (ET) (QAA, 2015), in particular the current ET on Transitions in, through and out of Higher Education (HE). The ETs encourage staff and students to engage with ideas and issues relevant to the theme. They stimulate further development of ET activities, involve students as partners in ET work and showcase good and innovative practice in a range of subject disciplines/programmes.

\section{Implementation}

Ethical approval was gained through the university ethics panel. The wider project adopted a mixed-methods case study approach. These included an online questionnaire co-developed by staff and co-researchers and distributed to all matriculated students on the PgCert $(n=$ 60 ) and a focus group interview with current students which was designed, facilitated and analysed by the student co-researchers. Written student evaluations from the Education in Action module were examined (this module runs across the first year of the e-PgCert). Online activity was measured through the BlackBoard Virtual Learning Environment (VLE) course tools function - these are reported elsewhere (MacDonald et al, 2016). Finally, and 


\section{Case Studies}

reported here, the programme team $(n=4)$ used de Bono's 'Six Thinking Hats' (de Bono, 1989, Appendix 1) to structure reflective discussions about their experiences of designing and running the programme. This process was captured on video and was available for further analysis in collaboration with the student co-researchers. The Education in Action module co-ordinator analysed the data from the VLE, using descriptive statistics. The project team conducted a collaborative thematic analysis of the qualitative data from the joint interview $(n=2)$, the module evaluations $(n=19)$ and the video $(n=4)$. We first colour-coded key words and phrases and then combined these to form such over-arching themes as 'lack of motivation', 'struggling students' and 'having positive debate', which we grouped under the theme 'Engagement with Learning'. These were validated using a peer-reviewed consensus approach at an awayday attended by the programme team and the student representatives (Figure 2).

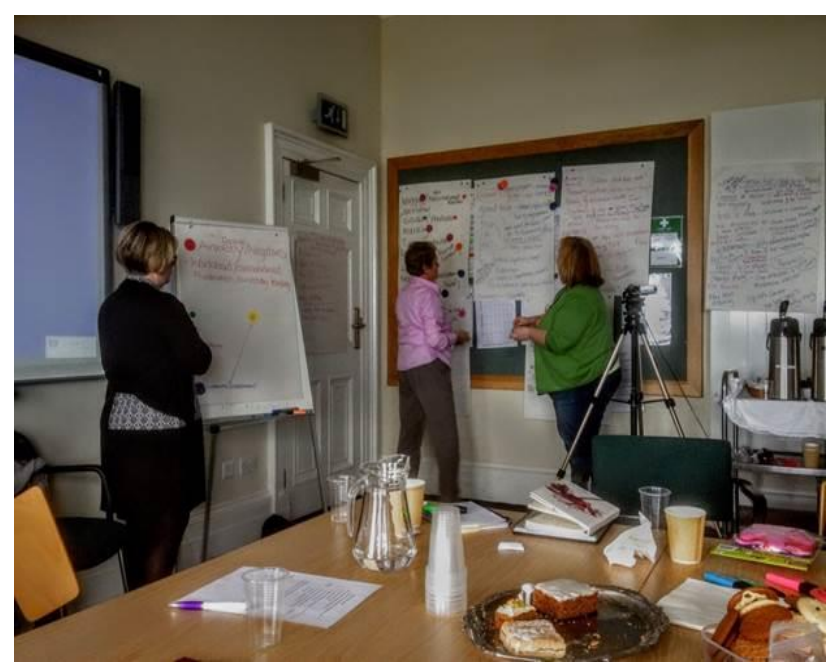

Figure 2. Co-creation through collaborative evaluation at staff and co-researcher awayday

\section{Discussion of practices: co-creation and the six thinking hats}

Traditional models of curriculum view students as passive recipients of learning, dependent on the transmission of knowledge by experts (Schiro, 2013). In contrast, co-creation of curriculum is a process whereby students and staff work together to develop pedagogical approaches (Bovill et al, 2016), with students as active participants in learning - a two-way process between lecturer and student (Bovill et al, op.cit.). In their co-creation model, Bovill et al, (op.cit., Figure 1) suggest that the student role in co-creation can be fourfold: as participant, co-researcher, co-designer or consultant. They suggest that co-creation increases student engagement and enhances learning and the relationships between staff and students. Barriers to co-creation include expectation by staff and students of a transmission approach to learning, student cynicism and lecturer under-estimation of students' abilities to co-create (Bovill et al, op.cit.). Strategies to address these issues include starting small, ensuring that co-creation is a voluntary activity and making cocreation meaningful rather than tokenistic. In keeping with these values, we wanted to ensure that the evaluation and re-design of our new e-PgCert was meaningful, small-scale and collaborative.

The evaluation of educational programmes forms an essential pillar of a university's quality assurance and enhancement activities. However, such complex evaluation methods as 


\section{Case Studies}

Kirkpatrick's (2001) or the CIPP model by Stake (1967), both in Stavropoulou and Stroubouki (2014), tend not to be sustainable, owing to staff and time resource limitations. Consequently, evaluators often synthesise different aspects of various models to generate creative solutions to unique evaluation situations (Stavropoulou and Stroubouki, op.cit.) - for example, programme leaders are tasked with ensuring the quality of their programme through their institution's QA process, which usually includes external examiners, students and external stakeholders, but will only rarely collect the kind of in-depth, 360-degree data suggested in published methodologies like Kirkpatrick's.

We were awarded a small internal 'PETL' grant ('Projects for the Enhancement of Teaching and Learning') to evaluate our new e-PgCert, using a resource-efficient, creative and cocreation approach that could potentially also highlight areas not commonly addressed in classic frameworks. As one author (IO) had previous positive experience of Edward de Bono's 'Six Thinking Hats' approach (de Bono, 1989), it was decided that it should form one element of the evaluation of the new programme. Whilst it is widely deployed in the school context, within critical-thinking skills strategies, relatively little has been written about its application in HE programme evaluation, though Erişen and Katmer-Bayraklı (2016) did successfully evaluate a teacher education programme with it.

De Bono's approach was originally designed to facilitate more effective, efficient, creative and inclusive meetings, where everyone is encouraged to speak her/his mind clearly on each issue. It does this by encouraging and inviting participants to articulate their views under differently-coloured 'thinking hats', each of which invites one's thinking to focus on one particular dimension of the topic under consideration. Everyone in the meeting is invited in turn to put on the same coloured hat and articulate her/his experience from that specific perspective. The chairperson usually wears the blue hat, which provides the overview of the entire process. For example, when wearing the black hat, participants focus on 'what did or does not work', whereas, with the white hat on, they consider only factual information - what happened - without expressing a view on it. The red hat invites participants to articulate any feelings they had or still have in relation to the issue under discussion. Thus, instead of a group of people meeting up and expressing views in an ad hoc way, with facts, positives, negatives, feelings and new ideas all mingled together, the 'thinking hats' framework offers order and coherence; it stimulates an awareness in speakers of what is relevant and instils the confidence to speak as appropriate for each hat - articulating, for example, personal feelings about concerns, secure in the knowledge that everyone else understands what they are about and that they won't be exposed to any criticism for so doing. Such a format makes it easier for everyone to accept others' views as simple 'red-hat thinking' and obviates any risk that exchanges become personal or acrimonious; it makes participants more empathetic, with greater appreciation of the nature of others' individual contributions to meetings, helps to separate out facts from feelings, attitudes and opinions, reduces the likelihood of attribution of comments to specific individuals and thereby allows for personal views to be aired freely... and so outcomes are therefore truly shared and equitable. The videos for each of the 'thinking hats' discussions can be found at Macdonald et al (2017). 


\section{Evaluation}

The sample consisted of students who were completely new to the online e-PgCert and some who had started the PgCert in earlier years as a blended programme, with some faceto-face teaching. Of the thirty per cent of students who completed the online survey, over half reported that this was their first experience of online learning. Five key themes emerged from the qualitative data (Figure 3). These were:

1. engagement with learning

2. workload

3. design

4. technology

5. emotional responses to online learning

These five themes have been subsumed into one over-arching theme: experiences of transitioning to online learning. Since the scope of this paper does not allow for extensive reporting of results, only some combined examples of the key findings from staff and students are presented in Table 1. These are further discussed in lessons learned.

\section{Experiences of transitioning to online learning}

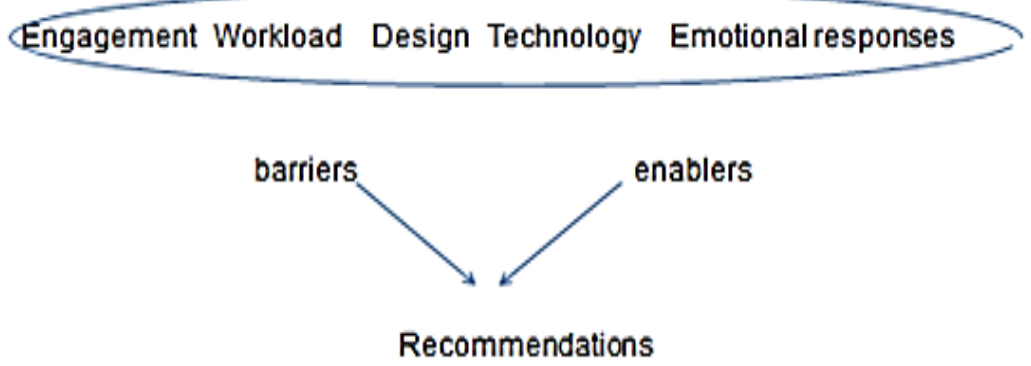

Figure 3. Thematic representation of qualitative results 
Table 1: Combined staff and student experiences of transitioning to online learning: some examples of enablers, barriers and recommendations.

\begin{tabular}{|c|c|c|c|}
\hline Theme & Enablers & Barriers & Recommendations \\
\hline $\begin{array}{l}\text { Workload } \\
\text { Management }\end{array}$ & $\begin{array}{ll}\text { - Structured } \\
\text { learning } \\
\text { activities help } \\
\text { workload }\end{array}$ & $\begin{array}{ll}\text { - } & \text { Pace was too fast } \\
\text { - } & \text { Work was } \\
& \text { overwhelming }\end{array}$ & $\begin{array}{l}\text { Reduce number of } \\
\text { discussions and content }\end{array}$ \\
\hline Design & $\begin{array}{l}\text { - Synchronous } \\
\text { video sessions } \\
\text { popular } \\
\text { - Like the flexibility } \\
\text { around work and } \\
\text { family }\end{array}$ & $\begin{array}{l}\text { - Too many } \\
\text { discussion areas } \\
\text { meant cross- } \\
\text { posting and } \\
\text { confusion about } \\
\text { where to post } \\
\text { - Some institutional } \\
\text { processes around } \\
\text { induction meant } \\
\text { late access for } \\
\text { some students }\end{array}$ & $\begin{array}{l}\text { - More recorded Adobe } \\
\text { Connect (AC) } \\
\text { (synchronous video } \\
\text { chat) sessions and } \\
\text { repeat the same ones } \\
\text { more than once. } \\
\text { Better management of } \\
\text { the discussion boards. } \\
\text { - Fix late induction }\end{array}$ \\
\hline Technology & $\begin{array}{l}\text { Synchronous } \\
\text { video sessions } \\
\text { are vital }\end{array}$ & $\begin{array}{l}\text { Synchronous } \\
\text { video sessions } \\
\text { can be clunky } \\
\text { and a lot of time } \\
\text { spent getting } \\
\text { people connected }\end{array}$ & $\begin{array}{l}\text { More recorded AC } \\
\text { sessions and repeat the } \\
\text { same ones more than } \\
\text { once }\end{array}$ \\
\hline $\begin{array}{l}\text { Emotional } \\
\text { Responses }\end{array}$ & $\begin{array}{l}\text { Feel part of a } \\
\text { community }\end{array}$ & $\begin{array}{l}\text { - "Didn't ask for an } \\
\text { online } \\
\text { programme" } \\
\text { Forced to } \\
\text { transition } \\
\text { - Feel intimidated } \\
\text { by some over- } \\
\text { enthusiastic } \\
\text { students who } \\
\text { don't follow } \\
\text { guidelines }\end{array}$ & $\begin{array}{l}\text { - More connect sessions } \\
\text { to encourage social } \\
\text { interaction } \\
\text { - Set up ground rules in } \\
\text { advance }\end{array}$ \\
\hline Engagement & $\begin{array}{l}\text { Get deeper } \\
\text { engagement } \\
\text { through online } \\
\text { discussions than } \\
\text { in face-to-face } \\
\text { discussions. } \\
\text { - Presence can be } \\
\text { achieved } \\
\text { through an } \\
\text { online medium }\end{array}$ & $\begin{array}{l}\text { Not enough } \\
\text { engagement in } \\
\text { online } \\
\text { discussions }\end{array}$ & $\begin{array}{l}\text { - Set up connect sessions } \\
\text { for signposting at the } \\
\text { beginning of each } \\
\text { module }\end{array}$ \\
\hline
\end{tabular}




\section{Case Studies}

\section{Lessons learned}

The students who were most dissatisfied with the change to an online programme were those who had initially signed up for a blended learning programme and found themselves without that choice in their second year. The assignments included online and paper submissions. These students' views were reflected in some of the comments in both the survey and interviews. We do not expect this response in future years, given that new students will be joining an online programme from the start. We introduced Adobe Connect video link sessions to enable synchronous face-to-face contact. However, these sessions proved very popular with new students as well as those transitioning to online. We therefore decided to embed such sessions early on in most modules. This approach now helps us to reinforce important study activities and to manage student expectations and further supports our approach to building an online community through peer support and tutor presence. We record each video session and offer repeat sessions to ensure that all students are included. Additionally, some of the live sessions are now set up as tutorials to discuss assignments or address particular topics.

Students and staff commented that the number of hours of study across some modules was too large for the credits awarded and, after staff reflections in the 'six thinking hats' discussions and further conversation with the co-researchers, re-design to reduce the volume and pace of study in some modules was deemed justified. Furthermore, we shall address the comments about equity across modules through deliberation at team meetings and student staff committees.

All parties commented on the clunky use of the interface used for online discussions. This is an institution-wide problem that has been raised at strategic level.

As with face-to-face group work, concerns arose in the programme about engagement with group work. We believe that we need to do more at the outset regarding setting expectations, particularly with regard to our philosophy. This philosophy embraces online rather than distance learning, and requires learners to work together as a community in joint 'e-tivities' rather than as 'lone wolfs' (Weimer, 2014)

Those who favoured the online delivery usually did so because of the flexibility it afforded them to fit their studies in with work, family and other commitments. Our learners are predominantly female, part-time, mature students who have part-time or full-time paid employment and caring duties besides their studies. Thus, online learning fits well with this demographic.

Institutional complications related to late admissions; therefore, access to the induction module left some students playing 'catch-up' from day one, which resulted in their feeling isolated and/or overwhelmed and in course tutors' experiencing extra workload. These difficulties have been resolved for next year. More work, however, is still to be done on the systems and processes for admission of these students: for example, there is a need to revise paperwork that advises attendance at the University for induction or library access. One size does not fit all and this practice can serve to alienate students further. 


\section{Case Studies}

Those who undertook the online induction module reported that it supports the transition to masters-level study, dealing with technology and navigating systems. It is hoped to roll this module out across the institution for customisation by other departments.

Some of our own staff are students on the programme and they felt that online learning disadvantaged them as it was hidden work that was not recognised. Students on a face-toface programme are allocated time to go to classes, but no such luxury is afforded to those in online learning. The same can be said for staff facilitating online learning. Not being present in a classroom does not equal 'no teaching' and we would argue that online facilitation is more time-consuming because of the frontloading that is required to set up the modules and the continuous discussions required to sustain a community of practice. Thus, online learning requires robust and realistic institutional support - through focused, effective and relevant communication with students - as well as recognition of the workload generated by the design, maintenance and delivery of online programmes.

Students and staff both reported that online discussions fostered deep engagement and learning. Tutors were pleasantly surprised at this, as they had assumed students would be less engaged than in a blended-learning mode. Conversely, some students felt intimidated by some of their peers who engaged intensively with the discussions, and perceived them as 'over-enthusiastic'. Students who come into discussion areas to find extensive posts by their peers in response to the topics or questions may then feel that they have nothing to add to the debate or that they need to go into even more depth to justify contributing to the discussion. Whilst our programme is entirely work-related, so that each student is required to draw on her/his unique professional and personal experiences, we now give suggestions as to length appropriate to discussion posts.

The staff experience of working with the two student representatives in reviewing the ePgCert was overwhelmingly positive, in that it provided significant added value to the authenticity of the process. The students also confirmed that working together with staff on this evaluation had been positive:

"I just wanted to say how much I enjoyed being with you all on the awayday. My very small part in the process was enlightening and it was a privilege to be involved. Each of you have inspired me on my journey in learning at different points and in different ways during the course so it was bit like being with my heroes for a day!"

Their involvement provided a perspective on the programme that may otherwise have been missed and allowed us critically to evaluate and refine some of our assumptions about students' experiences of the programme. They, in turn, reported that the co-creation activities assisted in the development of new skills: for example, in designing the student online survey, running the focus group and analysing qualitative data.

\section{Conclusion}

We used the 'Six Thinking Hats' approach as part of an evaluation project, with students in the role of representatives and co-researchers and involved in the collection, analysis and dissemination of data. Unlike Erişen and Katmer-Bayraklı (2016), we did not see the need to analyse all the data under the heading of each of the hats, instead combining the findings from this with other data generated by the co-researchers. The recommendations generated 


\section{Case Studies}

by the project fed directly into the redevelopment of the e-PgCert, some more successfully than others, and further evaluation will bring to light the extent to which these intended enhancements have been helpful. Our approach to co-creation of curriculum, working closely with students and employing an innovative approach to the generation of some of the data, has proved to be a relatively resource-effective approach. We continue to invite regular student engagement in review processes and all our modules already integrate the students' unique professional and personal experiences with scholarship and research. In the absence of funding, however, it is questionable whether students, in addition to fulfilling the role of student representative, would come forward to offer up their time for the collection and analysis of data and the writing-up of project findings. At the very least, however, the video material generated by the 'Six Thinking Hats' approach proved useful in engaging students in programme evaluation and we have obtained further funding to pilot this method, through an online environment, with students themselves. In the meantime, 'thinking hats' videos and the evaluation reports co-created with the students have been made available to students across the programme to generate continuous engagement and feedback, as well as to move closer to a sustained approach of integrated co-creation and co-evaluation of the programme.

\section{Reference list}

Bovill C. Cook-Sather, A. Felten, P. Millard, L. and Moore-Cherry, N. (2016) 'Addressing potential challenges in co-creating learning and teaching: overcoming resistance, navigating institutional norms and ensuring inclusivity in student-staff partnerships.' Higher Education 71, 195-208. Available at: http://link.springer.com/article/10.1007/s10734-015-9896-4 (Accessed: 22 February 2017).

Brown, M. Hughes, H. Keppell, M. Hard, N. and Smith, L. (2015) 'Stories from Students in Their First Semester of Distance Learning.' The International Review of Research in Open and Distributed Learning. 16(4). Available at:

http://www.irrodl.org/index.php/irrodl/article/view/1647/3448 (Accessed: 22 February 2017).

Butcher, J. and Rose-Adams, J. (2015) 'Part-time learners in open and distance learning: revisiting the critical importance of choice, flexibility and employability.' Open Learning: The Journal of Open, Distance and e-Learning. 30(2) 127-137. Available at: http://oro.open.ac.uk/43317/1/ UserData Documents jsb35 Desktop 02680513.2 015.pdf (Accessed: 22 February 2017).

De Bono, E. (1989) Six thinking hats. London: Penguin.

Erişen, Y. and Katmer-Bayraklı, V. (2016) 'Six Hat Thinking Technique in Program Evaluation: The Evaluation of the Quality of Mathematics Teacher Training Program in Turkey.' International Online Journal of Educational Sciences, 8(4), 31-45. Available at: http://www.iojes.net/userfiles/Article/lOJES 2257.pdf (Accessed: 22 February 2017).

Fragoso, A. Goncalves, T. Ribeiro, M. Monteiro, R. Quintas, H. Bago, J. Fonseca, H. and Santos, L. (2013) 'The transition of mature students to higher education: Challenging traditional concepts?' Studies in the Education of Adults. 45(1), 67-81. 


\section{Case Studies}

Jisc (2014) Developing digital literacies. Available at:

https://www.jisc.ac.uk/guides/developing-digital-literacies (Accessed: 16 May 2017).

MacDonald, K., Oberski I., Peacock, S., Irvine L., Stears A. and Christie K. (2016) Final report for the Projects for the Enhancement of Teaching and Learning (PETL) 2015/2016. An institutional response to transitioning online: a postgraduate case study. Edinburgh: Queen Margaret University.

MacDonald, K., Oberski I., Peacock, S., Irvine, L., Stears A. and Christie, K. (2016) Videos: e-PgCert \& Six Thinking Hats. Available at: http://tiny.cc/Co-creation. (Accessed: 20 February 2017).

O'Shea, S. Stone, C. and Delahunty, J. (2015) 'I feel like I am at university even though I am online. Exploring how students narrate their engagement with higher education institutions in an online learning environment.' Distance Education. 36(1), 41-58. Available at:

http://www.tandfonline.com/doi/full/10.1080/01587919.2015.1019970 (Accessed: 22 February 2017).

QAA (2015) Enhancement Themes. Available at:

http://www.enhancementthemes.ac.uk/docs/publications/overview-of-the-enhancementthemes.pdf?sfvrsn=8 (Accessed: 16 May 2017).

Schiro, M. (2013) 'Introduction to the curriculum ideologies.' In: Curriculum theory: conflicting visions and enduring concerns. 2nd ed. Thousand Oaks: Sage. Available at:

https://talkcurriculum.files.wordpress.com/2014/09/schiro-m-2012-introduction-to-thecurriculum-ideologies-in-curriculum-theory-2nd-ed.pdf (Accessed: 22 February 2017).

Stavropoulou, A. and Stroubouki, T. (2014) 'Evaluation of educational programmes - the contribution of history to modern evaluation thinking.' Health Science Journal. 8(2), 193-204. Available at: http://www.hsj.gr/medicine/evaluation-of-educational-programmes--thecontribution-of-history-to-modern-evaluation-thinking.pdf (Accessed: 22 February 2017).

Weimer, M. (2014) 'A Lone Wolf's approach to Group work.' Faculty Focus. Available at: http://www.facultyfocus.com/articles/teaching-professor-blog/lone-wolfs-approachgroup-work/ (Accessed: 20 February 2017). 